\title{
Adverse Effect on the Liver Biochemical Indices Following Dermal Exposure to Nigerian Bonny Light Crude Oil
}

\author{
Elechi, Udochi Alegua ${ }^{1}$, Alikor Chizindu $\mathrm{A}^{2^{*}}$ \\ ${ }^{1}$ B.Sc (RSU), M.Sc, Ignatius Ajuru University of Education Port Harcourt Nigeria \\ ${ }^{2}$ MBBS, MMED, FWACP, FCNPSA, Department of Medicine, University of Port Harcourt Harcourt Nigeria
}

DOI: $10.36348 /$ sibr.2019.v04i11.005

| Received: 11.11.2019| Accepted: 19.11.2019| Published: 21.11 .2019

*Corresponding author: Alikor Chizindu A

\section{Abstract}

The liver one of the vital organs of the human body. Its main job is to sieve the blood coming from the digestive tract, before passing it to the rest of the body. The liver detoxifies chemicals and metabolizes drugs. As it does so, the liver secretes bile that ends up back in the intestines. The liver also makes proteins important for blood clotting and other functions. The present study evaluated the adverse effect on the liver biochemical indices following dermal exposure to nigerian bonny light crude oil (BLCO) on 25 albino whister rats. 10 albino whister rats served as control while 15 albino whister rats were treated and grouped into 3 based on the treatment scheme $(1 \mathrm{ml}, 2 \mathrm{ml}$, and $3 \mathrm{ml})$. The body weight, serum biochemical assays of the liver where evaluated. The result obtained shows that there was an increase in the weight of the control (untreated) (101.20 \pm 2.781 and 111.40 \pm 2.591$)$ for weight before and after treatment respectively with a statistically significant for the control, while the treated group (BLCO) had a mean of $120.00 \pm 10.351$ (before treatment) and $106.33 \pm 10.431$ (after treatment) showing a significant decrease in the weight of the exposed albino whister rats when compared with the control. The biochemical assays shows that ALP increased as the dose increased (1ml) $14.00 \pm 0.00$, (2ml) $12.80 \pm 1.095$ and (3ml) $13.40 \pm 2.191$ respectively when compared with the control. The AST and ALT decreased as

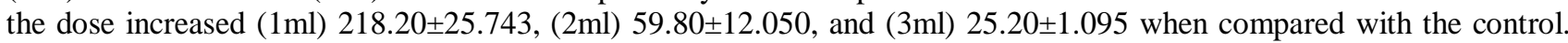

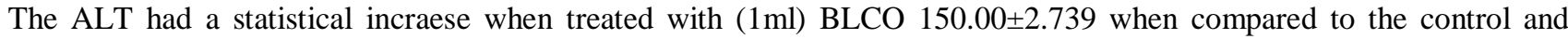
subsequently a decrease as the dose increased $(2 \mathrm{ml}) 72.00 \pm 21.909(3 \mathrm{ml})$ and $212.20 \pm 31.768$ respectively. Dermal exposure of these xenobiotics is almost certainly causing morphological alterations, soreness and necrosis of the cells of the liver and spleen, as observed from the histomicrographs. Chronic dermal exposure to BLCO had resulted in the absorption of its components into the blood stream and subsequent uptake by the liver. This has been shown to induce damaging effects on hepatocytes causing hepatotoxicity.

Keywords: Adverse effect, liver biochemical indices, dermal exposure, nigerian bonny light crude oil.

Copyright @ 2019: This is an open-access article distributed under the terms of the Creative Commons Attribution license which permits unrestricted use, distribution, and reproduction in any medium for non-commercial use (NonCommercial, or CC-BY-NC) provided the original author and source are credited.

\section{INTRODUCTION}

Bonny light crude oil (BLCO) is one of the major types of crude oil found in the Niger Delta region of Nigeria. It is classified as light crude oil $(\mathrm{SG}<0.82)$ and contains relatively low sulfur content in addition to asphaltenes, aromatic hydrocarbons, heavy metals and other compounds shown to exert varying degrees of toxicity $[1,2]$ The frequent dermal contact of the local population in the Niger Delta with BLCO is consequently a source of concern due to recurrent oil spills and insufficient remediation of impacted areas as well as its traditional use in the treatment of convulsion, poisoning, witchcraft, burns, foot rot, leg ulcers, eczema, rashes, arthritis and gastrointestinal disorders among other ailments $[3,4]$.
Studies have revealed that Bonny Light Crude Oil handling can lead to accumulation of some biometals which in-turn can be toxic to crucial organs of the body. Azubuike et al. [5] considered the neurotoxicity of Nigerian bonny light crude oil in rats. The study evaluated the effect of BLCO by determining the concentration of biometals and antioxidant status as well as histomorphometric analysis. The investigation was limited to adult male Wistar rats at the treatment dose of 0,200 , and $800 \mathrm{mg} / \mathrm{kg}(-1)$ of BLCO for a period of 7 days. In another study, [10] reported bioaccumulation of zinc, iron, lead, and nickel differing to copper in subjects exposed to BLCO. It was further pragmatic that the antioxidant system of the brain was affected and raised levels of hydrogen peroxide and lipid peroxidation was noted among subjects exposed to 
BLCO. BLCO treatment notably reduced molecular layer, granular layer, and density of Purkinje cells of the cerebellum through the Purkinje layer and maximum width of Purkinje cells were not affected. The study concluded that neurotoxicity of BLCO may be the result of oxidative stress as a consequence of the failure of biometal homeostasis and toxic injury from other constituents of BLCO. Similarly, in 2011 [5] in another study demonstrated the hepatorenal toxicity effect of BLCO. The study was performed with the use of oxidative stress indices to elucidate the exact nature and underlying mechanism of action. The study followed an oral route of administration of BLCO at various concentrations $\left(0,200,400\right.$, and $\left.800 \mathrm{mg} \mathrm{kg}^{-1}\right)$ for duration of one week, specifically adult male rats. The result noted that post-treatment exposure did not affect the kidney but a marked decreased effect was seen in liver weight when compared with control subjects at $800 \mathrm{mg} \mathrm{kg}^{-1}$.

Biochemical indices showed that BLCO exposure resulted in a dose-dependent increase of serum aminotransferases, total bilirubin, urea, and creatinine. On the other hand, activities of superoxide dismutase and catalase were considerably reduced, while $\gamma$-glutamyltransferase activity and the level of glutathione increased significantly in BLCO exposed subjects compared with control in both liver and kidney of rat. Kidney activities of glucose-6-phosphatase and 5'-nucleotidase markedly decreased in a dose-dependent manner in BLCO-exposed rats. In addition, the levels of hydrogen peroxide and lipid peroxidation significantly increased, dose-dependently in liver and kidney of BLCO-treated rats compared with control. BLCOtreated rats showed a marked deterioration of kidney palpable in cortical hemorrhages, tubular necrosis, protein casts, and cellular infiltration. However, no treatment-related liver histopathology was observed. The results suggested that BLCO elicits disruption of antioxidant status and concomitant elevation of hydrogen peroxide and lipid peroxidation differentially in liver and kidney of rats. The hepatorenal toxicity of BLCO may perhaps be due to the induction of oxidative stress in the liver and kidney [6].

In animals, the liver plays a central role in the metabolism of xenobiotics. It is involved in the transformation and clearing of chemical agents and is therefore susceptible to the toxins from these agents. Exposed chemical substances may practice detoxification and inactivation in the liver and become fewer harmful to the system or hepatic cell damage may occur as a result of their metabolism through the process of oxidation, reduction, hydroxylation and conjugation [7]. Abnormalities associated with liver function (hepatotoxicity) can be seen from altered activities of some serum transaminase enzymes, liver weight changes and histological distortions among other indicators [8-10].
In a previous study carried out by [11], the study showed that BLCO has hepatotoxic probables. The study reported that BLCO encouraged alterations in the liver mitochondria DNA content, cytoplasmic total hydrocarbon and calcium ion content in adult Albino whister rat exposed by intraperitoneal injection. They accounted that the concentration of crude oil total hydrocarbons (COTH) increased in a dose-related manner in the lungs more than in the liver at $2.5 \mathrm{ml} / \mathrm{kg}$ body weight, but was higher in the liver than the lungs at $5.0 \mathrm{ml} / \mathrm{kg}$ body weight when BLCO was administered to adult male guinea pigs by intraperitoneal injection (i.p) and that the definite activity of the mitochondrial 'marker' enzyme, succinic dehydrogenase increased markedly at $5.0 \mathrm{ml} / \mathrm{kg} \mathrm{BW}$ over the untreated controls. BLCO caused significant, dose-related, increases in total cellular DNA and chromatin (nuclear) DNA in the liver of adult male guinea-pigs treated by intraperitoneal injection (i.p) with $1.25,2.50$ and $5.0(\mathrm{ml} / \mathrm{kg} \mathrm{BW}) \mathrm{BLCO}$, and induced significant increases in glucose-6-phosphatase activity and regenerative DNA concentration in partially hepatectomized rat liver.

In a study carried out by [12]. Igwe and BobManuel, modifications in some hepatic function indices of male and female albino rats exposed to Bonny light crude oil (BLCO) by skin request were investigated. Sublethal dose $(500 \mathrm{mg} / \mathrm{kg}$ body weight) of the BLCO was applied to the shaved portion of the dorsal skin of the exposed rats while controls were similarly exposed to a placebo. After 30 days intervals, sets of rats were weighed, sacrificed and their blood collected for serum glutamic oxaloacetic transaminase (SGOT), serum glutamic pyruvic transaminase (SGPT) and serum albumin (SA) assay. The rat liver was also carefully excised, weighed and examined for histological changes. Results show that the relative liver weight decreased by $66.97 \%$ after 90 days in the males and increased by $9.25 \%$ after 90 days in females. SGOT and SGPT levels increased significantly $(\mathrm{p}<0.05)$ in both male and female rats during the study period. Changes in SGPT levels were more pronounced in the females compared to the males. The SA content decreased by $15.4 \%$ after 30 days and increased significantly $(\mathrm{p}<0.05)$ by $52.1 \%$ after 90 days for the males. In females, SA content increased by $12.5 \%$ after 30 days and decreased by $5.3 \%$ after 90 days. Histological examination of the liver cells of rats exposed for 90 days showed vacuolar degeneration, macrovesicular steatosis of hepatocytes and areas of necrosis evaluated to controls. These effects were more obvious among the female rats compared to the males. These results suggest that the prolonged dermal exposure of albino rats to BLCO which leads to absorption into the bloodstream and consequent uptake by the liver may exert a damaging effect on hepatocytes thereby causing hepatotoxicity. 


\section{ANIMAL PROTOCOL}

25 Albino whister rats weighing between $98 \mathrm{~g}$ to $126 \mathrm{~g}$ were obtained from the Biochemistry animal farm of the University of Port Harcourt and transferred to the animal unit of the Chemistry Research Laboratory, Ignatius Ajuru University of Education Rumuolumeni, Port Harcourt, and Rivers State, Nigeria. The Albino whister rats were housed in cages (metal cages) as this follows the revised EU Directive 86/609/EEC/Annex II, on Guidelines for Accommodation and Care of Laboratory Animals. They were fed with standard rodent feed and water ad libitum and maintained under well-ventilated condition [13]. The Albino more whist rat was allowed to acclimatize to the new laboratory condition for 5 days before treatment commenced.

The Albino whister rats were separated into two groups which include Control and test groups. The test group was made up of BLCO, which had 15 Albino whister rats, while the control had 10 rats. The test group was further divided into three sub-groups following the research design and dosage. The exposed group received sub-lethal dose $(1 \mathrm{ml}, 2 \mathrm{ml}$, and $3 \mathrm{ml})$ of BLCO respectively by topical skin application on $2 \mathrm{~cm}$ in the shaved portion of the dorsal skin while the control groups were not treated. This treatment was repeated every 24 hours throughout the duration of the study. The study lasted for fourteen (14) days. All the Albino whister rats were examined daily for physical and behavioral changes. The investigation was carried out based on approved institutional guidelines for the care and handling of laboratory animals as stipulated by the National and institutional guidelines for the protection of animal welfare during experiments [11].

\section{SAMPLE COLLECTION}

At the end of the study, the albino whister rats (designated as treated and Control), their weight was determined, anesthetized, sacrificed and their blood collected by cardiac puncture using uncontaminated syringe and needle. The blood was carefully transmitted into an EDTA bottle and left at room temperature to clot. Afterward, they were centrifuged at $4000 \mathrm{rpm}$ for 5 minutes. Separated Serum was carefully transferred into fresh clean dry bottles and stored at $50^{\circ} \mathrm{c}$ for enzyme assay. Afterward, the rats were further dissected and their liver carefully excised, cleaned of any attached strands and stored in a plain sample bottled filled with formalin for histopathology.

\section{HISTOPATHOLOGY INVESTIGATION}

A portion of the expunged rat liver and spleen was flat in $10 \%$ formalin, washed, dehydrated in isopropanol, washed by means of xylene and implanted in paraffin wax. The paraffin sections were prepared and stained with hematoxylin and eosin. Thin sections of the liver were made into permanent slides and examined under a microscope with photographic facility and photomicrographs were taken. The micrographs were investigated and construed by the pathologist. The processing, sectioning, staining, microscopic examination, and interpretation were carried out as described by [13].

\section{DATA ANALYSIS}

Results from the investigation will be expressed as the mean of triplicate determinations \pm standard deviation. Comparison between treated and corresponding control was made using SPSS Statistical Package for Social Sciences (SPSS) version 20. Group means were compared for significance at $p \leq 0.05$. Data were represented as the mean \pm standard deviation for $\mathrm{t}$ test of equal variants to determine the "p" value. A "p" value $<0.05$ was considered statistically significant.

Table 4.1 shows a dependent t-test of weight before and after of BLCO exposed albino white rats. The study observed a mean of $12<0.05 \pm 10.351$ and $106.33 \pm 10.431$ for weight before and after exposure according. Also, it showed evidence of statistical significance $(\mathrm{p}=<0.05)$ with a t-test value of 8.271 and a degree of freedom of 14

Table-1.1: Paired Samples Test for Weight before and Weight after for BLCO Exposed Rat

\begin{tabular}{|l|l|l|l|l|l|}
\hline & Mean \pm SD & t-test & Df & p-value & Remark \\
\hline Weight Before BLCO & $120.05 \pm 10.351$ & 8.271 & 14 & $<0.05$ & Sig \\
\hline Weight After BLCO & $106.33 \pm 10.431$ & & & & \\
\hline
\end{tabular}

Lastly, for intergroup mean weight comparison, table 4.2 illustrates mean variation between control subjects and the treatment exposed groups BLCO. The result showed evidence of statistically significant variation $(\mathrm{F}=11.573, \mathrm{df}=39$, $\mathrm{p}=<0.05)$ for weight before between control with BLCO. Whereas, weight, after revealed no statistically significant $(\mathrm{p}=0.38)$ discrepancy in the means of all the weights, compared. 
Biochemical Indices BLCO Mean Comparison of the control and the treatment doses Table-1.2: ANOVA of Control and Treatment Doses $(1 \mathrm{ml}, 2 \mathrm{ml} \mathrm{\&} \mathrm{3ml)} \mathrm{of} \mathrm{BLCO}$

\begin{tabular}{|c|c|c|c|c|c|c|c|c|}
\hline Variables & Control $(N=10)$ & $B L C O 1(N=5)$ & $B L C O 2(N=5)$ & $\operatorname{BLCO3}(N=5)$ & F-value & $D f$ & P-Value & Remark \\
\hline$A L P$ & $11.40 \pm 0.516$ & $14.00 \pm<0.05$ & $12.80 \pm 1.095$ & $13.40 \pm 2.191$ & 7.320 & 24 & $<0.05$ & Sig \\
\hline AST & $245.40 \pm 4.648$ & $218.20 \pm 25.743$ & $59.80 \pm 12.050$ & $25.20 \pm 1.095$ & 471.082 & 24 & $<0.05$ & Sig \\
\hline ALT & $143.60 \pm 13.426$ & $15<0.05 \pm 2.739$ & $72.00 \pm 21.909$ & $212.20 \pm 31.768$ & 45.405 & 24 & $<0.05$ & Sig \\
\hline AST/ALT & $1.720 \pm .1333$ & $1.458 \pm .1969$ & $.9560 \pm .5155$ & $.1214 \pm .0221$ & $<0.050$ & 24 & 1.00 & $N / S$ \\
\hline ALT/ALP & $12.67 \pm 1.721$ & $10.71 \pm .1956$ & $5.77 \pm 2.138$ & $16.54 \pm 5.398$ & 12.165 & 24 & $<0.05$ & Sig \\
\hline
\end{tabular}

Table-1.3: ANOVA of Treatment Doses (1ml, $2 \mathrm{ml} \& 3 \mathrm{ml})$ of BLCO

\begin{tabular}{|l|c|c|c|c|c|c|c|}
\hline Variables & BLCO1 $(\mathbf{N = 5})$ & BLCO2 $(\mathbf{N = 5})$ & BLCO3 $(\mathbf{N = 5})$ & F-value & Df & p-value & Remark \\
\hline ALP & $14.00 \pm<0.05$ & $12.80 \pm 1.095$ & $13.40 \pm 2.191$ & 0.900 & 14 & 0.43 & N/S \\
\hline AST & $218.20 \pm 25.743$ & $59.80 \pm 12.050$ & $25.20 \pm 1.095$ & 196.318 & 14 & $<0.05$ & $\mathrm{Sig}$ \\
\hline ALT & $15<0.05 \pm 2.739$ & $72.00 \pm 21.909$ & $212.20 \pm 31.768$ & 49.457 & 14 & $<0.05$ & $\mathrm{Sig}$ \\
\hline AST/ALT & $1.458 \pm .1969$ & $.9560 \pm .5155$ & $.1214 \pm .0221$ & $<0.050$ & 14 & 1.00 & $\mathrm{~N} / \mathrm{S}$ \\
\hline ALT/ALP & $10.71 \pm .1956$ & $5.77 \pm 2.138$ & $16.54 \pm 5.398$ & $<0.050$ & 14 & 1.00 & $\mathrm{~N} / \mathrm{S}$ \\
\hline
\end{tabular}

Table 1.2 shows the effect of bonny light crude oil (BLCO) on biochemical indices. From the table, administration of $1 \mathrm{ml}, 2 \mathrm{ml}$, and $3 \mathrm{ml}$ of Bonny light crude oil, caused a significant $(\mathrm{p}<0.05)$ dose-dependent increase in the GOT and GPT levels, while causing a significant decrease in the alkaline phosphatase level compared to the control.

The differences between treatment groups in the body weight of the experimental animals at the commencement of the experiment were put into consideration. In course of the experiment, the animals showed a progressive increase in body weight within the control groups. There was however, a much more significant decrease in body weight compared to the control group after the treatment duration with the different crude oil doses as shown on the table. Dermal administration of Bonny light crude oil (BLCO) produced significant effect on the body weight of the test groups as the dose was increased.

Result observed in animals exposed with BLCO and PMS showed a remarkable decrease $(p \leq 0.05)$ in the final body weight. This result as shown in tables 1.1 , is in agreement with the findings of [1417].

The increase in relative weights of liver (Hepatomegaly) observed in albino whister rats dermally exposed to BLCO and PMS is similar to the findings of [14], who reported an increase in the relative liver weight and a reduction in the percentage weight increase in rats following exposure to gasoline vapours. It has been reported that metabolism of aliphatic and aromatic hydrocarbons, the major constituents of petroleum and petroleum-derivatives, as well as other xenobiotics generates a significant increase in the level of free radical species in various tissues $[18,19]$. The generated reactive intermediates can interact and disrupt the cell membranes of the affected tissues thereby causing the tissue enzymes and other metabolites to leak out and increase the plasma concentrations as observed in this study. However, the decrease in overall body weight and organ weight may probably be an adaptive feature or a pathological response to the toxic compounds (hydrocarbon) present in the petroleum products.

Exposure of humans and animals to BLCO and PMS, which is growing in terms and escalating in usage of the environmental levels, might be extremely lethal to vital organs of the body. BLCO and PMS are used in various homes to run many types of engines, lamps and heaters and as an antidote to some illness. Most fuel oil entering the environment comes from systemic spills or leaking storage tanks. The biochemical parameters investigated showed a significant alteration $(\mathrm{p} \leq 0.05)$ when compared to the control in the BLCO treated groups. Treatment of albino whister rats with BLCO resulted to a considerable hepatic damage as obtained by the elevated levels of serum pointer enzymes: AST, ALT and ALP. These marker enzymes are cytoplasmic in derivation and are released into the circulation after cellular damage [20].

\section{REFERENCES}

1. Adedara, I. A., Ebokaiwe, A. P., \& Farombi, E. O. (2013). Tissues distribution of heavy metals and erythrocytes antioxidant status in rats exposed to Nigerian bonny light crude oil. Toxicology and industrial health, 29(2), 162-168.

2. IGWE, F., \& BOB-MANUEL, H. T. Hepatotoxic effects of the dermal exposure of albino rats to bonny light crude oil.

3. Orisakwe, O. E., Njan, A. A., Afonne, O. J., Orish, V. N., \& Udemezue, O. O. (2004). Investigation into the nephrotoxicity of Nigerian bonny light crude oil in albino rats. International Journal of Environmental Research and Public Health, 1(2), 106-110.

4. Orisakwe, O. E., Akumka, D. D., Afonne, O. J., \& Gamanniel, K. S. (2000). Investigation into the pharmacological basis for some of the folkloric uses of Bonny light crude oil in Nigeria. Indian Journal of Pharmacology, 32(3), 231-234. 
5. Ebokaiwe, A. P., \& Farombi, E. O. (2015). Influence of vitamin $\mathrm{E}$ and quercetin on Nigerian Bonny Light crude oil-induced neuronal and testicular toxicity in Wistar rats. Journal of basic and clinical physiology and pharmacology, 26(3), 223-231.

6. Ebokaiwe, A. P., Adedara, I. A., Owoeye, O., \& Farombi, E. O. (2013). Neurotoxicity of Nigerian bonny light crude oil in rats. Drug and chemical toxicology, 36(2), 187-195.

7. Khan, S., Irfan, M., \& Rahimtula, A. D. (1987) The hepatotoxic potential of a Prudhoe Bay crude oil: effect on mouse liver weight and composition. Toxicology, 46(1), 95-105.

8. Farombi, E. O., Adedara, I. A., Ebokaiwe, A. P., Teberen, R., \& Ehwerhemuepha, T. (2010). Nigerian Bonny light crude oil disrupts antioxidant systems in testes and sperm of rats. Archives of environmental contamination and toxicology, 59(1), 166-174.

9. Igwe, F. U., Dokubo, A., \& Ukpaka, C. P. (2016). Overview of crude oil toxicity: a potentia 1 health and environmental hazard in the Niger Delta. Nigerian Journal of Oil an $d$ Gas Technology, 2, 94-104.

10. Igwe, F. U., Wosu, H. W., \& Ogunka-Nnoka, C. U. Hepatic Effects of the Dermal Absorption of Emulsion Paint Solution by Albino Rats.

11. Oruambo, I., \& Jones, A. (2007). Alterations in the concentrations of liver mitochondrial DNA, cytoplasmic total hydrocarbon and calcium in guinea pigs after treatment with Nigerian light crude oil. International journal of environmental research and public health, 4(1), 23-27.

12. Jeffries, G.H. (1979). Toxic Drug-induced Liver Disease. In: Cecil Textbook of Medicine. Beeson, P.B (eds). $15^{\text {th }}$ Ed. W. B. Saunders, Philadephia, 1657 - 1659.
13. Toros, A. B., Yaşar, B., Özel, L., \& Kiliç, G. (2013). Histopathological changes in the rat liver exposed to chronic thinner inhalation. akademik gastroenteroloji dergisi, 12(3), 95-99.

14. Uboh, F. E., Akpanabiatu, M. I., Ndem, J. I., Alozie, Y., \& Ebong, P. E. (2009). Comparative nephrotoxic effect associated with exposure to diesel and gasoline vapours in rats. Journal of Toxicology and Environmental Health Sciences, 1(4), 068-074.

15. Murtala, B. A., Abdul, W. O., \& Akinyemi, A. A. (2012). Bioaccumulation of heavy metals in fish (Hydrocynus forskahlii, Hyperopisus bebe occidentalis and Clarias gariepinus) organs in downstream Ogun coastal water, Nigeria. Journal of Agricultural Science, 4(11), 51.

16. Isaac, A.A., Roy, T., Azubike P. E., Theresa E., \& Ebenezer O. F., (2011). Induction of oxidative stress in liver and kidney of rats exposed to Nigerian bonny light crude oil. Environ Toxicol https://doi.org/10.1002/tox.20660.

17. Zakrzewski, S. F. (2002). Environmental Toxicology. Oxford University Press. ( $3^{\text {rd }}$ ed.):334.

18. Lam, O.T., Khan, S., Irfan, M., \& Raimtula, A. D. (1994). Toxic Drug-induced Liver Disease. In: Cecil Textbook of Medicine.Beeson, P.B (eds). 15th Ed. W. B. Saunders, Philadephia, 1657-1659.

19. Bondy, F.T., Oliver, T., \& Wounter, W. (1995). Biochemical changes in the serum and liver of albino rats exposed to petroleum samples (gasoline, kerosene and crude oil). J.Appl. Sci. Environ. Mgt, 5(1): 97-100.

20. Lin, O.B.E., \& Fabian, A.F. (2000). Crude oil poisoning in a 2 year old Nigerian - a case report. Anil Aggrawal's Internet Journal of Forensic Medicine and Toxicology, 6(2): 1-5. 